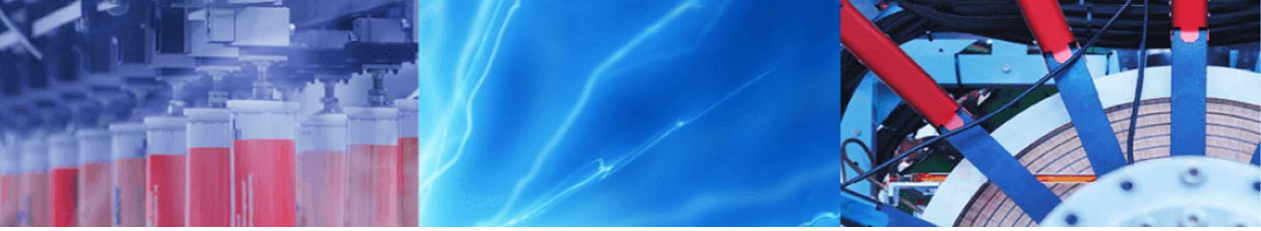

Research Article

\title{
Enhanced laccase expression and azo dye decolourization during co-interaction of Trametes versicolor and Phanerochaete chrysosporium
}

\author{
Jatinder Singh ${ }^{1} \cdot$ Anamika Das $^{1} \cdot$ K. N. Yogalakshmi ${ }^{1}$
}

Received: 19 October 2019 / Accepted: 28 April 2020 / Published online: 19 May 2020

(c) Springer Nature Switzerland AG 2020

\begin{abstract}
In the present investigation, azophloxine dye decolourization with lignolytic enzyme producing white rot fungi, Trametes versicolour (TV) and Phanerochaete chrysosporium (PC) co-cultures, was investigated. Co-culturing of TV and PC extended the laccase activity by 8.2 times as compared to monocultivation of TV. Phanerochaete chrysosporium, a non-laccase producing fungus, produced the enzyme due to hyphal modifications and synergistic interaction with Trametes versicolour. The crude laccase extracted from TV + PC co-cultures showed $87.6 \%$ decolourization when subjected to azophloxine dye for $48 \mathrm{~h}$. Contrary, laccase extracted from TV self-pairing plates showed decolourization of $14.4 \%$. Henceforth, this investigation demonstrated that co-culturing of two white rot strains improved dye decolourization by increasing laccase enzymatic action.
\end{abstract}

Keywords Laccase · Azo dye · Decolourization · White rot fungi · Co-culturing · Trametes versicolor $\cdot$ Phanerochaete chrysosporium

\section{Introduction}

Commercially 100,000 dyes are used worldwide throughout the year. Out of one million tons of dyes that is produced every year, $50 \%$ of the unbound dyes are lost to the environment as textile dye effluent [1]. The textile industry effluent when released into the water bodies (lakes, rivers and ponds) reduces the penetration of sunlight and causes severe damage to the photosynthetic activity. It decreases the oxygen concentration in the water bodies and leads to the death of the aquatic organisms [2]. Textile dyes adversely effects the natural biological cycles of the aquatic living system due to their toxicity-linked metabolic stress, growth reduction, neurosensory damage and death. Among the synthetic dyes, around $70 \%$ of dyes used in textile industries belong to azo dyes. Azo dyes are toxic, mutagenic and carcinogenic in nature [1].
The adverse effects of dyes necessitate the treatment of textile effluent before it enters into the environment [3]. Physicochemical methods like adsorption, sedimentation, flocculation, coagulation and ozonation are usually carried out. Although these methods are effective, still their application is limited due to various demerits such as huge space requirement, chemical sludge production and high cost [4].

Low-cost and eco-friendly nature of biological methods have made them popular among other physical and chemical methods of treatment. Fungal strains like Rhizopus arrhizus, Aspergillus niger, Rhizopus oryzae Pleurotus florida and Rhizoctonia solani have already been reported in dye degradation $[5,6]$. Among the various fungal strains, white rot fungi (WRF) have been reported as the most effective fungi in dye decolourization process. Phanerochaete chrysosporium, Pleurotus ostreatus

K. N. Yogalakshmi, yogalakshmi25@gmail.com | 'Department of Environmental Science and Technology, School of Environment and Earth Sciences, Central University of Punjab, Bathinda, Punjab 151001, India. 
and Tramateus. versicolor are the few popular WRF that is extensively reported in the previous literature for dye decolourization $[7,8]$. WRF produces nonspecific extracellular oxidative enzymes such as laccase, lignin peroxidase (LiP) and manganese peroxidase (MnP) that biotransforms and detoxifies the dyes [9]. Due to the nonspecific nature of the lignolytic enzymes (laccase, lignin peroxidase and manganese peroxidase), the use of WRF has been directly associated with bioremediation of dyes [10,11].

Among the lignolytic enzymes, laccase expressed a great potential in dye degradation as it does not require a mediator or a costly co-substrate, except molecular oxygen $[12,13]$. Laccase enzyme is a multi-copper containing protein that catalyses the oxidation of a various organic and inorganic substrates simultaneously by reducing molecular oxygen into water. It removes hydrogen atom from the hydroxyl group by electron oxidation and generates nontoxic by-products during the dye degradation process [14]. Mehra et al. [15] reported that phenolic compounds induced the production of laccase enzyme in fungus. Laccase oxidizes the phenolic group of the azo dye with just one electron, creating a phenoxy radical which is successively trailed by oxidation to form a carbonium particle. Water does a nucleophilic attack on the carbon of the phenolic ring and results in the formation of 3-diazenyl-benzenesulfonic corrosive (III) and 1, 2-naphthoquinone [14]. The objective of this study was to estimate the potential of laccase enzyme in the decolourization of azophloxine dye using co-culturing technique. Among the various WRF strains reported in the literature, $T$. versicolor and P. chrysosporium were selected on the basis of their potential to degrade complex organic pollutants [16]. P. chrysosporium itself does not produce laccase, but it triggers the laccase production in co-culture of Aspergillus niger and Aspergillus oryzae [17]. In the same way, it can also be hypothesized that co-culturing of T. versicolor and P. chrysosporium can enhance the laccase production resulting in improved and rapid decolourization of dyes.

In the present study, the growth rate and laccase activity during interspecific interaction of $T$. versicolor and $P$. chrysosporium on agar medium were determined. A comparative study on the enzymatic decolourization of azophloxine dye using crude laccase enzyme extracted from the different zones of pair culture $(T V+T V$ and $P C+P C)$ on agar plates was carried out. This new approach will contribute to the potential applicability of co-culturing the WRF strains in enhanced dye decolourization in wastewater effluent. The aim of the present study was to evaluate dye decolourization efficacy of two fungi P. chrysosporium and T. versicolor using effective co-culture technology.

\section{Materials and methods}

\subsection{Chemicals}

2,2'-Azino-bis-3-ethylbenzothiazoline-6-sulphonic acid (ABTS) was purchased from Sigma-Aldrich. Azophloxine dye, potato dextrose agar (PDA) and all other chemicals were purchased from Hi-Media, India. All chemicals and reagents used in the study were of analytical grade.

\subsection{Fungal strains and culture conditions}

Trametes versicolor (NCIM-1086) and Phanerochaete chrysosporium (NCIM-1106) fungal strains were procured from National Collection for Industrial Microorganisms (NCIM), Pune, India. Cultures of $T$. versicolor (NCIM-1086) and $P$. chrysosporium (NCIM-1106) were preserved on potato dextrose agar (PDA) medium at $\mathrm{pH} 6$ and $28^{\circ} \mathrm{C}$. Fungal plugs of size $\sim 10 \mathrm{~mm}$ from fully cultures grown on PDA plates were used as an inoculum and sub-cultured regularly at intervals of $15 \mathrm{~d}$.

\subsection{Paired interaction tests on agar plates}

The qualitative laccase activity assay was determined during the intra- and interspecific interactions of $T$. versicolor and $P$. chrysosporium on PDA agar plates [18]. Fungal plugs of size $\sim 10 \mathrm{~mm}$ were cut from actively growing mycelium, inoculated on PDA agar plates and incubated for $5 \mathrm{~d}$ at $28^{\circ} \mathrm{C}$. Self-pairing interaction plates consisted of fungal plugs of the same species and interspecific interaction plates consisted of fungal plugs of $T$. versicolor and $P$. chrysosporium. Plates of $T$. versicolor (TV + TV) and $P$. chrysosporium (PC $+\mathrm{PC}$ ) were used as a control. The fungal growth and interaction among cultures on PDA plates were observed at regular intervals of $24 \mathrm{~h}$. The laccase production in the PDA plates was estimated qualitatively by swamping ABTS for $5 \mathrm{~min}$. The colour developed on the plates indicated the extracellular activity of laccase enzyme. The intensity of developed colour was evaluated visually and articulated in arbitrary units ranging from 0 to 5 [19].

\subsection{Dye decolourization studies}

Azophloxine dye of concentration $50 \mathrm{mg} / \mathrm{L}$ was added to autoclaved PDA media. The PDA plates containing $50 \mathrm{mg} / \mathrm{L}$ azophloxine dye were inoculated with $\sim 10 \mathrm{~mm}$ actively growing fungal plugs of $T$. versicolor and $P$. chrysosporium and incubated at $28^{\circ} \mathrm{C}$. The dye decolourization in interspecies (TV $+\mathrm{PC}$ ) and self-pairing of 
fungal strains (T. versicolor (TV + TV) and P. chrysosporium $(P C+P C)$ ) on agar plates were evaluated.

\subsection{Crude enzyme extraction}

The enzymatic activity in the agar plates was determined at the point where the hyphae of $T$. versicolor and $P$. chrysosporium (TV + PC) and the hyphae of TV + TV and $P C+P C$ meet each other. Fungal plugs were cut from each of the three regions ( $T, P$ and TP) of interacting mycelia as depicted in Fig. 1. In the figure, regions $T$ and $P$ represent $T$. versicolor and $P$. chrysosporium, respectively, and TP corresponds to interspecific interaction zone of both fungal strains (TV $+P C)$. The cut plugs were transferred to culture tubes containing sodium acetate buffer $(\mathrm{pH}-4.5)$ and incubated in an orbital shaker at $150 \mathrm{rpm}$ for $12 \mathrm{~h}$ at $4{ }^{\circ} \mathrm{C}$. The extract was centrifuged at $4000 \mathrm{rpm}$ for $10 \mathrm{~min}$ at $4{ }^{\circ} \mathrm{C}$, and the supernatant was filtered using Whatman filter paper no. 1 to remove fungal mycelia. The filtrate was collected and again filtered through syringe filters $(0.45 \mu \mathrm{m})$ and stored at $4{ }^{\circ} \mathrm{C}$ for enzyme assay [20].

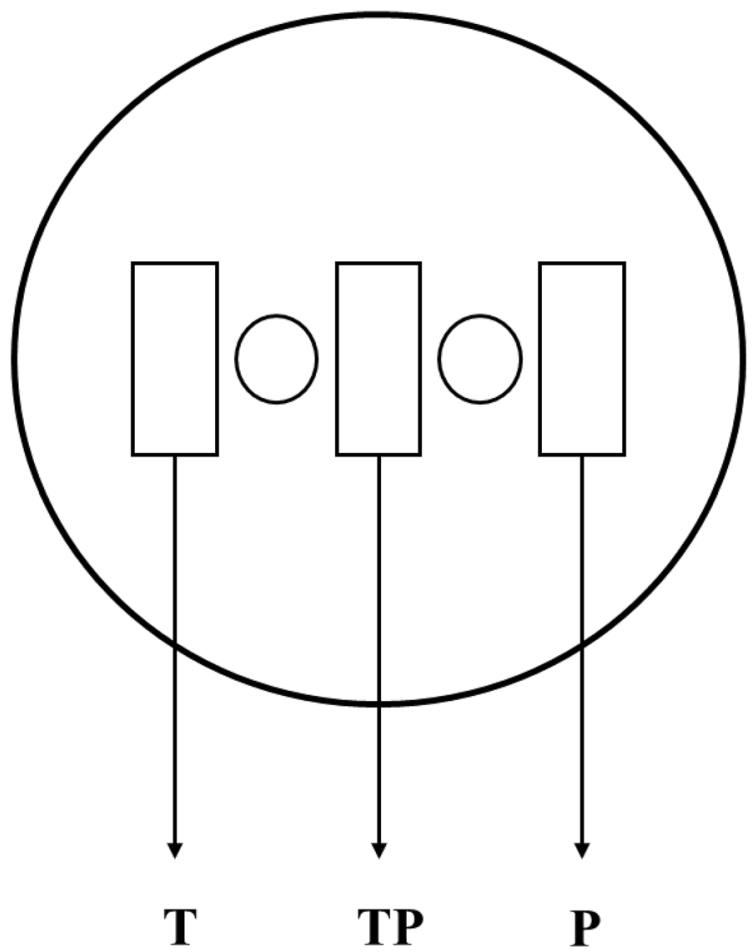

Fig. 1 Regions of fungal inoculation and enzyme extraction: Circular region shows the inoculation point, and rectangles are sampling region in interacting mycelia for enzyme extraction ( $P$ : $P$. chrysosporium $\mathrm{T}$ : T. versicolor)

\subsection{Determination of Crude laccase enzyme activity}

Using ABTS as the oxidation substrate the activity of crude laccase enzyme was determined spectrophotometrically at $420 \mathrm{~nm}\left(\varepsilon=3600 \mathrm{M}^{-1} \mathrm{~cm}^{-1}\right)$. Briefly, the reaction mixture contained $250 \mu \mathrm{L}$ of crude enzyme extract and $1 \mathrm{~mL}$ of $0.5 \mathrm{mM}$ ABTS in $20 \mathrm{mM}$ sodium acetate buffer ( $\mathrm{pH} 4.5)$ [21]. One unit of enzyme (laccase) activity was defined as the amount of enzyme required to oxidize $1 \mathrm{mmol}$ of substrate (ABTS) per minute. All the experiments were run in triplicate.

\subsection{Dye decolourization assay with crude enzyme extract}

The crude enzyme was mixed with sodium acetate buffer containing azophloxine dye of concentration $50 \mathrm{mg} / \mathrm{L}$. The mixture was incubated at $150 \mathrm{rpm}, 30^{\circ} \mathrm{C}$ for $48 \mathrm{~h}$. The dye solution was adjusted to $\mathrm{pH} 4.5$ before incubating with the crude enzyme extract. The decrease in intensity of dye in the sample was measured in spectrophotometer at a wavelength of $533 \mathrm{~nm}$. The dye decolourization per cent was calculated as per the formula (1).

Dye decolourization rate $(\%)=\frac{A_{\mathrm{o}}-A_{t}}{A_{\mathrm{o}}}-\times 100$

where $A_{0}$ and $A_{t}$ are initial and final absorbance, respectively, at $\lambda_{\max }(533 \mathrm{~nm})$.

\subsection{Statistical analysis}

All the experiments were performed in triplicate $(n=3)$. Mean and standard deviation were calculated with Microsoft Office Excel 2007 spreadsheet, and values were represented as mean $\pm S D(n=3)$. The error bars in the figures represent standard deviation $(n=3)$.

\section{Results and discussion}

\subsection{Hyphal interaction in agar plates}

P. chrysosporium and T. versicolor are white rot fungi with potential to secrete laccase enzyme. Their behaviour during intraspecific and interspecific interaction was studied in PDA plates. Figure 2 (a) and (b) depicts the intraspecific interaction, while Fig. $2 c$ depicts the interspecific interaction. From the figure, it is clearly evident that $P$. chrysosporium during its intraspecific pairing showed luxurious growth and occupied the entire plate unlike the plates with $T$. versicolor that showed an 
Fig. 2 Co-culturing of $P$. chrysosporium and T. versicolor a self-pairing of $P$. chrysosporium, b interspecific pairing of $T$. versicolor and $P$. chrysosporium. c Self-pairing of $T$. versicolor

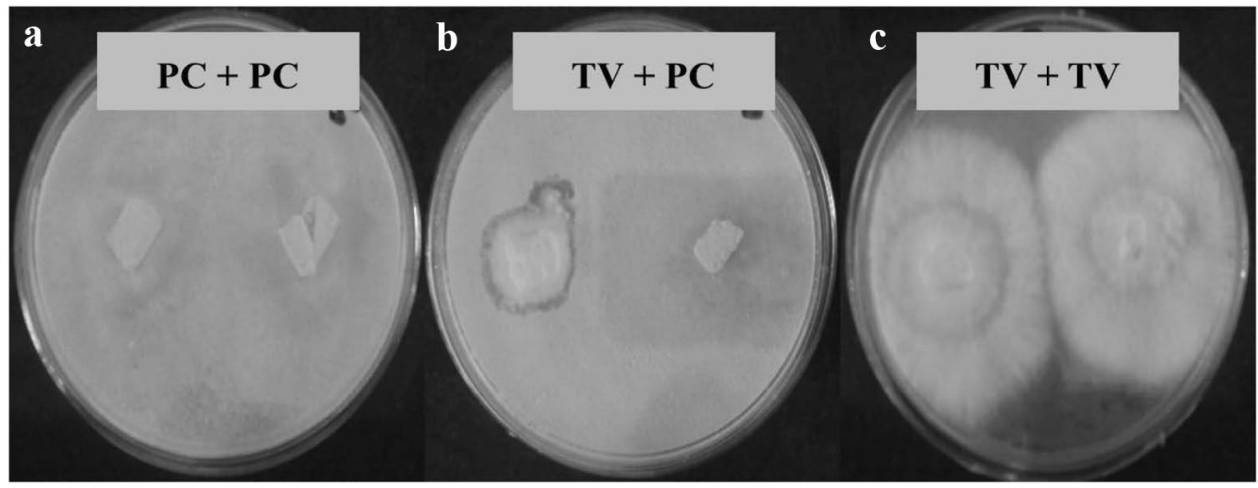

extension of growth to $3.5 \mathrm{~cm}$ away from the point of inoculation after 6 days of incubation. Intraspecies interaction showed no deadlocks or replacements unlike interspecific interactions. Plates with $T$. versicolor and $P$. chrysosporium showed changes in the hyphal morphology at the point of interaction between the two mycelia. The mycelial of $P$. chrysosporium surrounded the mycelium of $T$. versicolor and became dense. Moreover, at the junction of interaction a deadlock occurred (Fig. 2c). According to Kennedy [22], interspecific interaction between two fungi results in the alteration of mycelial functioning, distribution and nutrient allocation. Qian and Chen [25] in their study too reported the occurrence of deadlock interaction during the co-culturing of $T$. versicolor and P. chrysosporium.

\subsection{Laccase activity and inter- and intraspecific interaction}

The laccase activity during interspecific and intraspecific interaction was determined by flooding the ABTS in the Petri plates (Fig. 3). Laccase activity in self-pairing $T$. versicolor (TV + TV), P. chrysosporium ( $\mathrm{PC}+\mathrm{PC})$ and pairing of $T$. versicolor and $P$. chrysosporium $(\mathrm{TV}+\mathrm{PC})$ is depicted in Fig. 3a-c, respectively. Blue colour development indicates the laccase production. From the figure, it can be inferred that $P$. chrysosporium did not show laccase production during self-pairing and hence no colour formation was observed. T. versicolor self-pairing plates showed laccase production at the mycelial edges as indicated by the blue colour development. Contrary, co-cultured plates exhibited a different pattern of laccase production. A high laccase activity was observed in the co-cultured (TV and PC) plates, especially in the zone of interaction of the mycelia. No such interaction was observed in the self-pairing
Fig. 3 Laccase enzyme localized through ABTS addition on interaction regions on PDA agar plates. a Self-pairing of $P$. chrysosporium. b Self-pairing of $T$. versicolor and $\mathbf{c}$ Interspecific pairing of $P$. chrysosporium and $T$. versicolor ( $\mathrm{f}$ : front side, $\mathrm{r}$ : rear side)

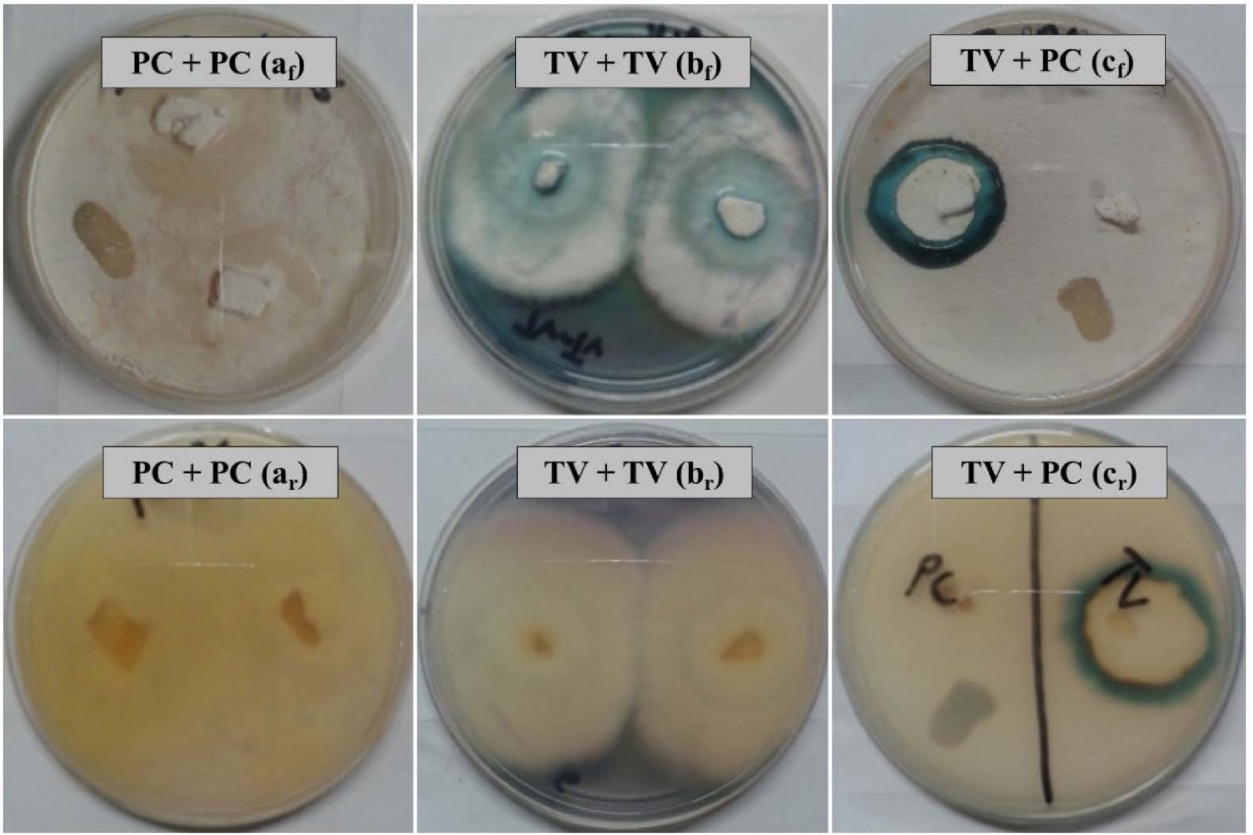


plates. Briefly, maximum laccase activity was observed in the TP zone followed by the T zone. No laccase activity was observed in the $P$ zone as $P$. chrysosporium does not produce laccase enzyme. Studies by Martinez et al. [24] and Qian [16] also confirmed that $P$. chrysosporium does not produce laccase enzyme. $P$. chrysosporium produced laccase only in the presence of other fungal species [17]. The maximum laccase activity was observed on the 5th day of incubation after the two fungal mycelia met each other on the $3^{\text {rd }}$ of incubation. The laccase activity was found to decrease after the 5 th day.

Mycelial invasion of one fungus might have induced the other fungi to produce laccase during its defence [23]. A similar observation was also reported by Hiscox et al. [20] during the interaction of Trametes versicolor and Bjerkandera adjusta on malt agar plates, thereby supporting the hypothesis of Score et al. [23]. Hiscox et al. [20] also reported that during interspecific interactions the production of oxidative enzymes increases. The results of this study are also comparable to that of Lakovlev and Stenlid [18], that reported a high laccase activity at the interaction zone in the PDA plate. Qian and Chen [16] also reported that $P$. chrysosporium stimulated and increased the laccase activity in $T$. versicolor.

\subsection{Effect of co-culturing on dye decolourization}

The influence of T. versicolor, P. chrysosporium and their cocultures in azophloxine dye decolourization was assessed in PDA plates incubated for 5 days with $50 \mathrm{mg} / \mathrm{L}$ of dye. Figure 4 illustrates the dye decolourization potential of P. chrysosporium $\left(\mathrm{a}_{\mathrm{f}}\right)$, T. versicolor $\left(\mathrm{b}_{\mathrm{f}}\right)$ and co-cultured ( $P$. chrysosporium and $T$. versicolor $\mathrm{c}_{\mathrm{r}}$ ) fungal species. The results of the study indicate that after 5 days of incubation, plates inoculated with TV $+\mathrm{PC}\left(\mathrm{c}_{\mathrm{r}}\right)$ co-cultures showed $100 \%$ dye decolourization as compared to monocultured plates of $P$. chrysosporium $\left(\mathrm{a}_{\mathrm{r}}\right)$ and $T$. versicolor $\left(\mathrm{b}_{\mathrm{r}}\right)$ which showed a minimum decolourization. A control run without any fungal inoculation showed no decolourization. The complete dye decolourization in co-cultured plates may be attributed to the improved laccase production due to the synergistic action of the fungal species. Generation of free radicals such as reactive oxygen species (ROS) is a result of oxidative stress condition during hyphal interaction owing to the competition among fungi for nutrient and space. This proves coordination among species in dye decolourization $[6,26]$. Moreover, an enhanced expression of phenol oxidase could have also attributed to dye decolourization [27]. The formation of phenol oxidase can be evidenced by the appearance of dark brown colour at the overlapping of fungal $(T V+P C)$ hyphae (Fig. $\left.3 C_{r}\right)$. According to Cheng and Chan [28], intermediate compounds obtained during metabolic degradation might have been utilized effectively for rigorous metabolic activities, thereby making such synergistic combinations more effective.

\subsection{Dye decolourization by crude enzyme extract}

The crude enzyme was extracted from the interspecific interacting areas of TV + PC and intraspecific interacting areas of TV $+T V$, and their activities were quantified. Table 1 summarizes the laccase activity of the TV + PC and

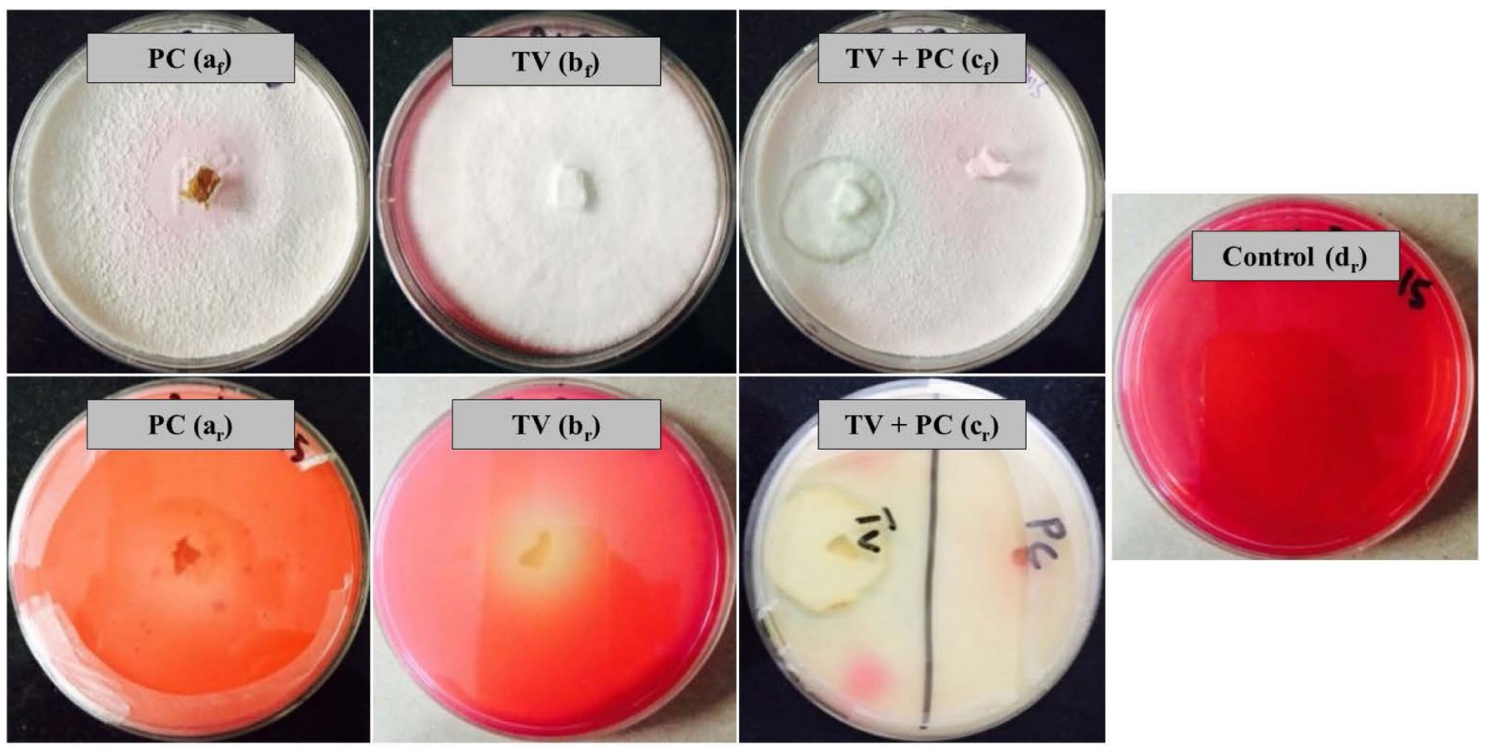

Fig. 4 Decolourization of azophloxine dye by $P$. chrysosporium $\left(\mathrm{a}_{\mathrm{f}}\right.$ and $\left.\mathrm{a}_{\mathrm{r}}\right), T$. versicolor $\left(\mathrm{b}_{\mathrm{f}}\right.$ and $\left.\mathrm{b}_{\mathrm{r}}\right)$ and co-cultivation of $T$. versicolor and $P$. chrysosporium $\left(\mathrm{C}_{\mathrm{f}}\right.$ and $\left.\mathrm{C}_{\mathrm{r}}\right)$ and $\left(\mathrm{d}_{\mathrm{r}}\right)$ control plate 
Table 1 Laccase enzyme activities of mono- and co-cultivation of TV-TV, PC-PC and TV-PC

\begin{tabular}{lll}
\hline S. no. & Strain & Laccase $(\mathrm{U} / \mathrm{L})$ \\
\hline 1. & TV-TV & $104.15 \pm 3.12$ \\
2. & PC-PC & nd \\
3. & TV-PC & $861.11 \pm 15.32$ \\
\hline
\end{tabular}

that co-culturing can be efficiently used for degradation of dyes to maintain tighter stringent government standards with respect to disposal of dye effluents into the environment.

\section{Conclusion}

TV + TV cultures after 5 days of incubation. Maximum laccase activity of $861.11 \pm 15.32 \mathrm{U} / \mathrm{L}$ was recorded in crude enzyme extracted from co-cultured plates. Around 8.2 times higher laccase activity was observed in co-cultured plates as compared to TV + TV plates that recorded laccase activity of $104.15 \pm 3.12 \mathrm{U} / \mathrm{L}$. The efficiency of the crude fungal laccase obtained from TV + PC and TV + TV was assessed in azophloxine dye solution (Fig. 5). During the 48-h incubation period, the crude fungal laccase obtained from TV + PC showed a decolourization efficiency of $50 \%$ at 24th hour and $87.6 \%$ at the 48th hour. Likewise, crude laccase of TV + TV showed a maximum decolourization efficiency of $14.4 \%$ after 48 h of incubation. The results of the present study are in complete agreement with Dwivedi et al. [29] and Wang et al. [30] that reported enhanced lignocellulolytic enzymes during the co-culturing of Pleurotus ostreatus and Penicillium oxalicum. In co-culture systems, the combined and inductive effects of various enzymes can work synergistically over monocultures [31,32]. The results of the present study signify

The observations recorded in this study confirmed the production of 8.2 times higher laccase activity at the interaction zone of co-cultured $T$. versicolor and $P$. chrysosporium as compared to self-pairing plates of $T$. versicolor. The T. versicolor and $P$. chrysosporium co-cultures showed excellent potential and decolourized the azophloxine dye completely in PDA plates incubated for 5 days. The crude fungal laccase extracted from the co-cultured and self-pairing plates of T. versicolor also showed azophloxine dye decolourization of $87.6 \%$ and $14.4 \%$, respectively, within $48 \mathrm{~h}$ of incubation. Co-culturing has brought changes in the hyphal morphology in the fungal strains and initiated synergistic interaction to enhance the laccase production and dye decolourization. Thus, co-culturing of fungal strains holds great potential for the decolourization of recalcitrant textile dyes.
Fig. 5 Decolourization profiles of azophloxine dye by crude enzyme extract of TV-PC and monocultivation of TV

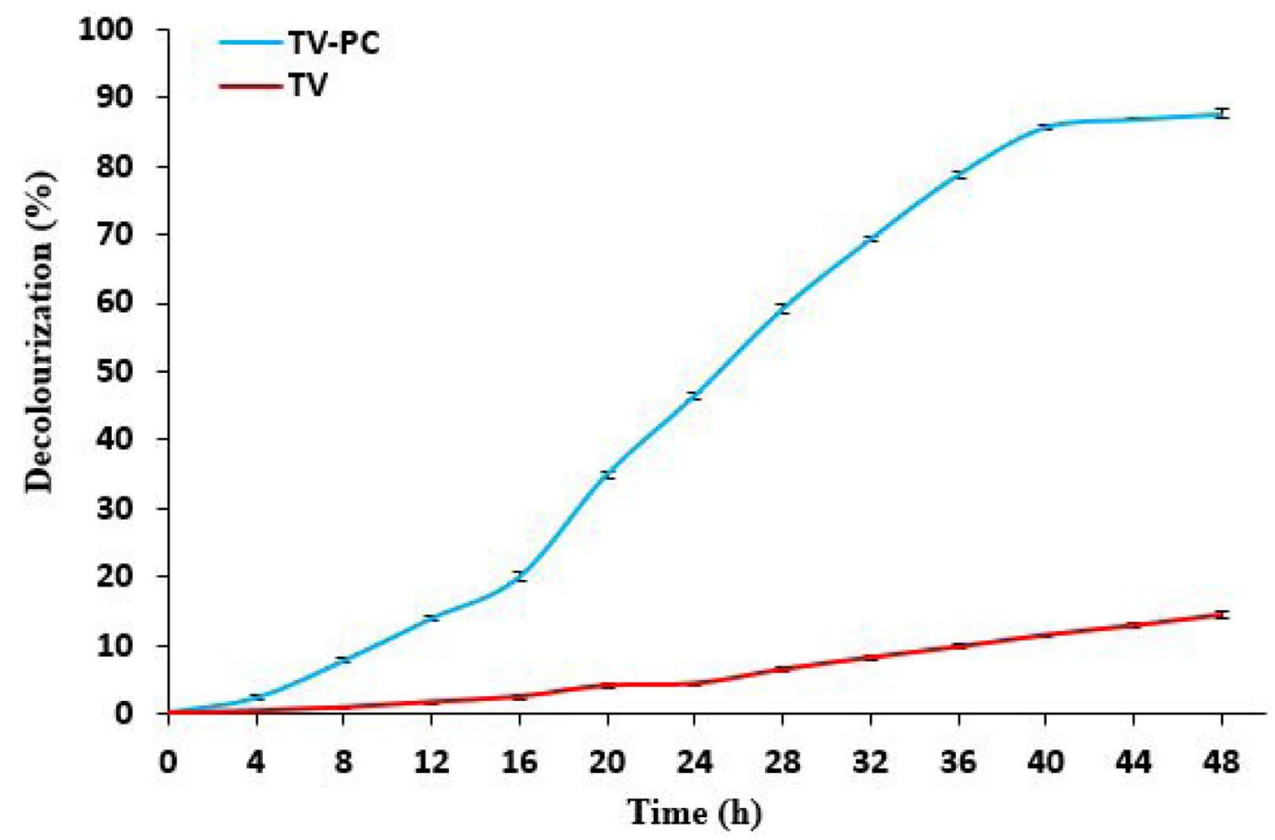


Acknowledgements The authors are grateful to University Grants Commission (UGC), New Delhi, India, for providing financial support.

\section{Compliance with ethical standards}

Conflict of interest The authors declare that they have no conflict of interest.

Human and animal rights This article does not contain any studies involving animals or human participants performed by any of the authors.

\section{References}

1. Garg SK, Tripathi M (2017) Microbial strategies for discoloration and detoxification of azo dyes from textile effluents. Res J Microbiol 12:1-19. https://doi.org/10.3923/jm.2017.1.19

2. Lang W, Sirisansaneeyakul S, Ngiwsara L, Mendes S, Martins LO, Okuyama M, Kimura A (2013) Characterization of a new oxygeninsensitive azoreductase from Brevibacillus laterosporus TISTR1911: toward dye decolorization using a packed-bed metal affinity reactor. Bioresour Technol 150:298-306. https://doi.org/10.1016/j.biort ech.2013.09.124

3. Ayed L, Mahdhi A, Cheref A, Bakhrouf A (2011) Decolorization and degradation of azo dye Methyl Red by an isolated Sphingomonas paucimobilis: biotoxicity and metabolites characterization. Desalination 274(272):277. https://doi.org/10.1016/j.desal.2011.02.024

4. Robinson T, McMullan G, Marchant R, Nigam P (2001) Remediation of dyes in textile effluent: a critical review on current treatment technologies with a proposed alternative. Bioresour Technol 77:247-255. https://doi.org/10.1016/S0960-8524(00)00080-8

5. Ramya M, Anusha B, Kalavathy S, Devilaksmi S (2007) Biodecolorization and biodegradation of Reactive Blue by Aspergillus sp. Afr J Biotech 6:1441-1445

6. Kumari S, Naraian R (2016) Decolorization of synthetic brilliant green carpet industry dye through fungal co-culture technology. J Environ Manag 180:172-179. https://doi.org/10.1016/j.jenvm an.2016.04.060

7. Gomaa OM, Linz JE, Reddy CA (2008) Decolorization of Victoria blue by the white rot fungus, Phanerochaete chrysosporium. World J Microbiol Biotechnol 24:2349-2356. https://doi.org/10.1016/j. jscs.2011.10.010

8. Bosco F, Mollea C, Ruggeri B (2017) Decolorization of Congo Red by Phanerochaete chrysosporium: the role of biosorption and biodegradation. Environ Technol 38:2581-2588. https://doi. org/10.1080/09593330.2016.1271019

9. Banat IM, Nigam P, Singh D, Marchant R (1996) Microbial decolorization of textile-dye containing effluents: a review. Bioresour Technol 58:217-227

10. Arantes V, Milagres AMF (2007) The synergistic action of ligninolytic enzymes ( $\mathrm{MnP}$ and Laccase) and $\mathrm{Fe}^{3+}$ reducing activity from white-rot fungi for degradation of Azure B. Enzyme Microb Technol 42:17-22. https://doi.org/10.1016/j.enzmictec.2007.07.017

11. Rodrigues-Couto S (2017) Industrial and environmental applications of white-rot fungi. Mycosphere 8:456-466. https://doi. org/10.5943/mycosphere/8/3/7

12. Strong PJ, Claus H (2011) Laccase: a review of its past and its future in bioremediation. Crit Rev Environ Sci Technol 41(373):434. https ://doi.org/10.1080/10643380902945706

13. Mirzadeh SS, Khezri SM, Rezaei S, Forootanfar $\mathrm{H}$, Mahvi AH, Faramarzi MA (2014) Decolorization of two synthetic dyes using the purified laccase of Paraconiothyrium variabile immobilized on porous silica beads. J Environ Health Sci 12:6. https://doi. org/10.1186/2052-336X-12-6

14. Yang J, Li W, Ng TB, Deng X, Lin J, Ye X (2017) Laccases: production, expression regulation, and applications in pharmaceutical biodegradation. Front Microbiol 8:832. https://doi.org/10.3389/ fmicb.2017.00832

15. Mehra R, Muschiol J, Meyer AS, Kepp KP (2018) A structural-chemical explanation of fungal laccase activity. Sci Rep 8:17285

16. Qian Y (2005) Effect of nitrogen concentration in culture mediums on growth and enzyme production of Phanerochaete chrysosporium. J Environ Sci 17:190-193

17. Hu HL, Van den Brink J, Gruben BS, Wösten HAB, Gu JD, De Vries RP (2011) Improved enzyme production by co-cultivation of Aspergillus niger and Aspergillus oryzae and with other fungi. Int Biodeter Biodegr 65:248-252. https://doi.org/10.1016/j.ibiod.2010.11.008

18. Lakovlev A, Stenlid J (2000) Spatiotemporal patterns of laccase activity in interacting mycelia of wood-decaying basidiomycete fungi. Microb Ecol 39:236-245. https://doi.org/10.1007/s0024 80000022

19. Davidson RW (1938) Differentiation of wood-decay fungi by their reactions on gallic or tannic acid medium. J Agric Res 57:683-695

20. Hiscox J, Baldrian P, Rogers HJ, Boddy L (2010) Changes in oxidative enzyme activity during interspecific mycelial interactions involving the white-rot fungus Trametes versicolor. Fungal Genet Biol 47:562-571. https://doi.org/10.1016/j.fgb.2010.03.007

21. Johannes C, Majcherczyk A (2000) Natural mediators in the oxidation of polycyclic aromatic hydrocarbons by laccase mediator systems. Appl Environ Microbiol 66:524-528

22. Kennedy P (2010) Ectomycorrhizal fungi and interspecific competition: species interactions, community structure, coexistence mechanisms, and future research directions. New Phytol 187:895910. https://doi.org/10.1111/j.1469-8137.2010.03399.x

23. Score AJ, Palfreyman JW, White NA (1997) Extracellular phenoloxidase and peroxidase enzyme production during interspecific fungal interactions. Int Biodeter Biodegr 39:225-233

24. Martinez D, Larrondo LF, Putnam N, Gelpke MDS, Huang K, Chapman J, Coutinho PM (2004) Genome sequence of the lignocellulose degrading fungus Phanerochaete chrysosporium strain RP78. Nat Biotechnol 22:695-700. https://doi.org/10.1038/nbt967

25. Qian L, Chen B (2012) Enhanced oxidation of benzo [a] pyrene by crude enzyme extracts produced during interspecific fungal interaction of Trametes versicolor and Phanerochaete chrysosporium. J Environ Sci 24:1639-1646. https://doi.org/10.1016/ S1001-0742(11)61056-5

26. Chi Y, Hatakka A, Maijala P (2007) Can co-culturing of two white-rot fungi increase lignin degradation and the production of lignindegrading enzymes? Int Biodeter Biodegr 59:32-39. https://doi. org/10.1016/j.ibiod.2006.06.025

27. Henson JM, Butler MJ, Day AW (1999) The dark side of the mycelium: melanins of phytopathogenic fungi. Annu Rev Phytopathol 37:447-471. https://doi.org/10.1146/annurev.phyto.37.1.447

28. Chen BY, Chang JS (2007) Assessment upon species evolution of mixed consortia for azo dye decolorization. J Chin Inst Chem Eng, 38:259-266. https://doi.org/10.1016/j.jcice.2007.04.002

29. Dwivedi UN, Singh P, Pandey VP, Kumar A (2011) Structure-function relationship among bacterial, fungal and plant laccases. $J$ Mol Catal B Enzym 68:117-128. https://doi.org/10.1016/j.molca tb.2010.11.002

30. Wang Y, Shao Y, Zou X, Yang M, Guo L (2018) Synergistic action between extracellular products from white-rot fungus and cellulase significantly improves enzymatic hydrolysis. Bioeng 9:178185. https://doi.org/10.1080/21655979.2017.1308991

31. Belenguer A, Duncan SH, Calder AG, Holtrop G, Louis P, Lobley GE, Flint HJ (2006) Two routes of metabolic cross-feeding between Bifidobacterium adolescentis and butyrate-producing anaerobes 
from the human gut. App Environ Microbiol 72:3593-3599. https ://doi.org/10.1128/AEM.72.5.3593-3599.2006

32. Copete-Pertuz LS, Alandete-Novoa F, Plácido J, Correa-Londoño GA, Mora-Martínez AL (2019) Enhancement of ligninolytic enzymes production and decolourising activity in Leptosphaerulina sp. by co-cultivation with Trichoderma viride and Aspergillus terreus. Sci Total Environ 646:1536-1545. https://doi.org/10.1016/j. scitotenv.2018.07.387
Publisher's Note Springer Nature remains neutral with regard to jurisdictional claims in published maps and institutional affiliations.

\section{SN Applied Sciences}

